\title{
The fate of the nuclear matrix-associated-region-binding protein SATB1 during apoptosis
}

\author{
J Gotzmann ${ }^{\star, 1}$, M Meissner ${ }^{1}$ and C Gerner ${ }^{1}$ \\ 1 Institute of Tumor Biology - Cancer Research, University of Vienna, A-1090 \\ Vienna, Austria \\ * Corresponding author: J Gotzmann, Institute of Tumor Biology - Cancer \\ Research, University of Vienna, Borschkegasse 8a, A-1090 Vienna, Austria. \\ Tel: +43-1-4277-65234; Fax: +43-1-4277-9651; \\ E-mail: josef.gotzmann@univie.ac.at
}

Received 2.9.99; revised 22.12.99; accepted 28.12.99

Edited by SJ Martin

\begin{abstract}
Special AT-rich sequence-binding protein 1 (SATB1), predominantly expressed in thymocytes, was identified as a component of the nuclear matrix protein fraction. Programmed cell death of Jurkat T-cells was induced by various stimuli in Fas-dependent and -independent fashion. During apoptosis, but not during necrosis, SATB1 was cleaved, as rapidly as was lamin $B$, in a caspase-dependent way yielding a stable $70 \mathrm{kDa}$ fragment. The same result was obtained for apoptotic HL60-cells. We constructed various deletion constructs of SATB1, expressing protein chimeras tagged with green fluorescent protein (GFP). Transient transfection of these into Jurkat or HeLa cells followed by initiation of apoptosis allowed us to map the potential caspase-6 cleavage site VEMD to the $\mathrm{N}$-terminal third of SATB1, leaving an intact DNA-binding domain in the C-terminal part of the protein. Our results suggest that apoptosis-specific breakdown of SATB1, a transcriptional activator of the CD8a gene, might be of physiological relevance during thymic clonal deletion and apoptosis of peripheral T-lymphoid cells. Cell Death and Differentiation (2000) 7, 425-438.
\end{abstract}

Keywords: SATB1; MAR/SAR; nuclear matrix; apoptosis; cell death; caspases

Abbreviations: SATB1, special AT-rich binding protein 1; M/SAR, matrix/scaffold attachment region; NMPs, nuclear matrix proteins; GFP, green fluorescent protein; PCD, programmed cell death; -fmk, -fluoromethylketone; -cmk, -chloromethylketone; - $\mathrm{CHO}$, -aldehyde; TLCK, N- $\alpha$-p-tosyl-L-lysine chloromethylketone; TPCK, N-tosyl-Lphenylalanine-chloromethylketone; fl, full length

\section{Introduction}

Apoptosis is the currently used synonym for programmed cell death (PCD), a highly ordered and active suicide, determined on a genetic basis and highly conserved throughout evolution. ${ }^{1-4} \mathrm{PCD}$ is involved in normal development, tissue homeostasis, immune response and tumor control. A variety of human diseases arise from abnormalities in apoptosis execution, resulting either in excessive removal of cells (e.g. neurodegenerative diseases $)^{5}$ or in inadequate accumulation of cells (e.g. cancer) ${ }^{6-8}$ Apoptosis functionally antagonizes mitosis, as exemplified by a disturbance of a normal balance between proliferation and cell death during neoplastic progression, a crucial step in malignant conversion. ${ }^{9}$ Even in most advanced malignancies the cell death machinery remains intact, but cells lack or repress regulatory mechanisms to activate the death program sufficiently to balance enhanced cell production. ${ }^{10}$

Necrosis, a different form of cell death, is caused by severe damage of cellular homeostasis. ${ }^{5,11}$ Necrotic cells swell and lose the protective function of the plasma membrane, concomitant with anucleolytic pyknosis. Contrarily, apoptotic cells shrink, leaving the plasma membrane almost intact, and undergo profound nuclear changes, accompanied by chromatin, condensation, oligonucleosomal DNA cleavage and cellular fragmentation resulting in the appearance of apoptotic bodies. ${ }^{12,13}$ Apoptosis can be triggered by a variety of inducers, ranging from ionizing radiation, DNA-damaging agents, lack of growth factors, chemotherapeutic agents to activators of cell surface death receptors. ${ }^{14-16}$ Despite the divergence of death inducers, most of the resulting signaling cascades seem to converge into a common execution pathway, characterized by activation of a family of cysteine proteases, the caspases. Most commonly, highly ordered intra- and intermolecular activation of caspases leads to proteolytic destruction of a continuously growing list of target proteins. ${ }^{3,17}$ Accumulating evidence suggests, that these caspase target molecules constitute elements for structural and functional integrity of the cell and particularly that of the nucleus. ${ }^{18}$

The nuclear structure is considered to be dependent on an intrinsic interaction of nucleic acids with a proteinaceous scaffold of nuclear matrix proteins. ${ }^{19,20}$ A key role in maintaining structure has also been proposed for AT-rich DNA-sequences, termed matrix-attachment regions (MARs) ${ }^{21}$ or scaffold-attachment regions (SARs). ${ }^{22}$ These are implied in a specific anchorage of chromatin loops to the nuclear scaffold. ${ }^{23}$ MARs are often found at the boundaries of transcription units, possibly defining actively transcribed genes, but are also detectable near regulatory sequences, such as enhancers. Furthermore, MARs have been demonstrated to stimulate expression of reporter genes and to enhance chromatin accessibility, when stably integrated into the genome. ${ }^{24,25}$

A variety of MAR-binding proteins have recently been identified and characterized. These proteins, mostly considered as functional constituents of a nuclear matrix, such as topoisomerase $1 \mathrm{I},{ }^{26}$ special-AT-rich binding protein 1 (SATB1), ${ }^{27}$ histone $\mathrm{H1},{ }^{28}$ scaffold-attachment factors (SAFs) $A$ and $B,{ }^{29,30}$ nucleolin, ${ }^{31}$ mutant $p 53,{ }^{32}$ lamins $\mathrm{B} 1,{ }^{33} \mathrm{~A}$ and $\mathrm{C},{ }^{34}$ and a $114 \mathrm{kDa}$ breast cancer-specific 
MAR-binding protein, ${ }^{35}$ are keyplayers in fundamental nuclear processes. Accumulating evidence suggests, that SATB1, and possibly other MAR-binding proteins, may be involved in tissue-specific gene regulation. SAF-A, ${ }^{36}$ lamin $B 1^{37,38}$ and lamins $A$ and $C^{39}$ have been reported to be cleaved during apoptosis, as is true for other nuclear proteins, such as NuMa, ${ }^{12,40,41}$ poly-(ADP-ribose)-polymerase $(\mathrm{PARP}),{ }^{42}$ topoisomerase $\mathrm{I},{ }^{43}$ and the lamin $\mathrm{B}$ receptor. ${ }^{44}$

The list of nuclear matrix proteins serving as caspase substrates is increasing, the cell systems and death inducers, however, used to collect these data are unfortunately extremely heterogeneous. The lack of systematic data on proteins of the nuclear scaffold affected during apoptosis of a particular cell type prompted us to increase our knowledge from previous work. ${ }^{45}$ In rat fibroblasts we observed time-dependent alterations of NMPs during apoptosis, induced by withdrawal of serum. ${ }^{45}$ We changed to a well established human cell system and comprehensively studied Fas-induced apoptosis of Jurkat T-lymphoblastoid cells (Gerner et al. in preparation). In the course of our studies we identified SATB1 as being cleaved into a stable $70 \mathrm{kDa}$ fragment at early stages of apoptosis.

SATB1 is a component of the nuclear matrix ${ }^{46}$ predominantly expressed in the thymus. It was originally cloned on the basis of its ability to bind AT-rich MAR-stretches, displaying a so-called ATC-context with high base-unpairing potential under superhelical strain. ${ }^{27}$ SATB1 possesses a homeodomain, resembling those of transcription factors, functionally promoting the DNA-binding capacity of SATB1. ${ }^{47}$ SATB1 was found to suppress transcription driven by the MMTV (mouse mammary tumor virus)-promoter. ${ }^{48}$ In contrast, Banan and co-workers ${ }^{49}$ ascribed transcriptional activation of the CD8a gene to SATB1, antagonizing CDP/ Cux. CDP/Cux is, likewise, a homeodomain MAR-binding protein functionally repressing transcription of target genes by competing e.g. with SATB1 for regulatory binding sites. An implication of SATB1 function in thymus development is supported by showing maximum expression of the protein during the first wave of T-cell maturation. ${ }^{50}$

Characterization of SATB1 cleavage revealed proteolysis to occur specifically during apoptosis and we provide evidence for a possible involvement of caspases. Triggering apoptosis in different cells and using various inducers did not change the cleavage pattern. We applied the GFPtechnology to further characterize the biochemical and cell biological events, successfully mapped the potential cleavage site, and studied subcellular changes of SATB1 mutants. Our results suggest that apoptosis-specific breakdown of SATB1 might be physiologically relevant, particularly during apoptosis of thymic and peripheral T-cells.

\section{Results}

\section{Time course of apoptosis and cleavage of SATB1} in Jurkat cells

Based on our previous data on NMPs affected during apoptosis of serum-starved rat fibroblasts, ${ }^{45}$ we extended the systematic analysis to a well-defined human system, namely Fas-mediated cell death of Jurkat T-lymphoblastoid cells. Under serum-free conditions, as commonly used, a considerable percentage (up to $30-35 \%$ ) of untreated cells entered apoptosis (Figure 1A). Apoptosis was, therefore, induced in medium supplemented with $1 \%$ fetal calf serum (FCS). This significantly reduced apoptosis in controls while the kinetics and incidence of apoptosis after anti-Fas treatment showed negligible differences (Figure 1A).

Candidate proteins, proteolyzed in apoptosis, were registered by comparison of high-resolution $2 \mathrm{D}$-gel patterns and identified by classical and modern methods of proteome analysis (Gerner et al. in preparation). Among the proteins degraded, SATB1, a MAR-binding protein highly expressed in the thymus, ${ }^{27}$ raised our interest based on its functional properties in influencing transcription.

Figure 1B (upper panel) clearly demonstrates the cleavage kinetics of SATB1 during Fas-mediated cell death in Jurkat cells. SATB1, although its calculated $M_{r}$ is 86000 , migrated at a $M_{r}$ of 103000 in SDS-PAGE. This unexpected electrophoretic mobility has previously been reported. $^{27}$ Cleavage of SATB1 was first detectable $2 \mathrm{~h}$ after application of anti-Fas antibody and progressed with ongoing increase of apoptotic cells, leading to substantial conversion of the native $103 \mathrm{kDa}$ protein to a $70 \mathrm{kDa}$ cleavage polypeptide within the first $8 \mathrm{~h}$ (Figure 1B, upper right panel). This proteolysis could not be observed in controls (Figure 1B, upper left panel). The same cleavage pattern was obtained using the protein kinase inhibitor staurosporine to induce PCD (Figure 1B, lower panel). The kinetics of apoptosis was similar to Fas-induced, the conversion to the $70 \mathrm{kDa}$ fragment appeared to be more complete. In both cases approximately $70-90 \%$ of SATB1 were degraded after a period of $8-10 \mathrm{~h}$. The proteolytic product was stable over a period of $16 \mathrm{~h}$ of ongoing apoptosis (data not shown). The remaining fragment of SATB1 with an expected molecular weight of $25-30 \mathrm{kDa}$ was not recognized by anti-SATB1 antibodies.

\section{SATB1 cleavage is apoptosis-specific and caspase-dependent}

Western analysis of other nuclear proteins, lamin B and nucleolin (C23), served as internal cleavage and loading controls for Fas-induced cell death (Figure 2A). While lamin B, a well characterized target of caspase- $6,{ }^{37}$ was digested at a kinetics similar to that of SATB1, the nucleolar marker protein nucleolin remained unaffected (Figure 2A), as has been described for HL-60 cells by Martelli and co-workers. ${ }^{51}$ Furthermore, the cytosolic protein GAPDH was not cleaved (Figure 2A), but was found translocated to the nucleus as early as $1 \mathrm{~h}$ past anti-Fas application (data not shown), as described in more detail for neuronal and non-neuronal cell systems, respectively. ${ }^{52}$

To check the specificity of SATB1 proteolysis during apoptosis, we induced necrosis by depletion of endogenous ATP by oligomycin (O) or a combined oligomycin/ staurosporine (OST) treatment. The latter was found to accelerate necrosis, measured by the trypan blue exclusion assay (data not shown). Immunostaining of lysates from 

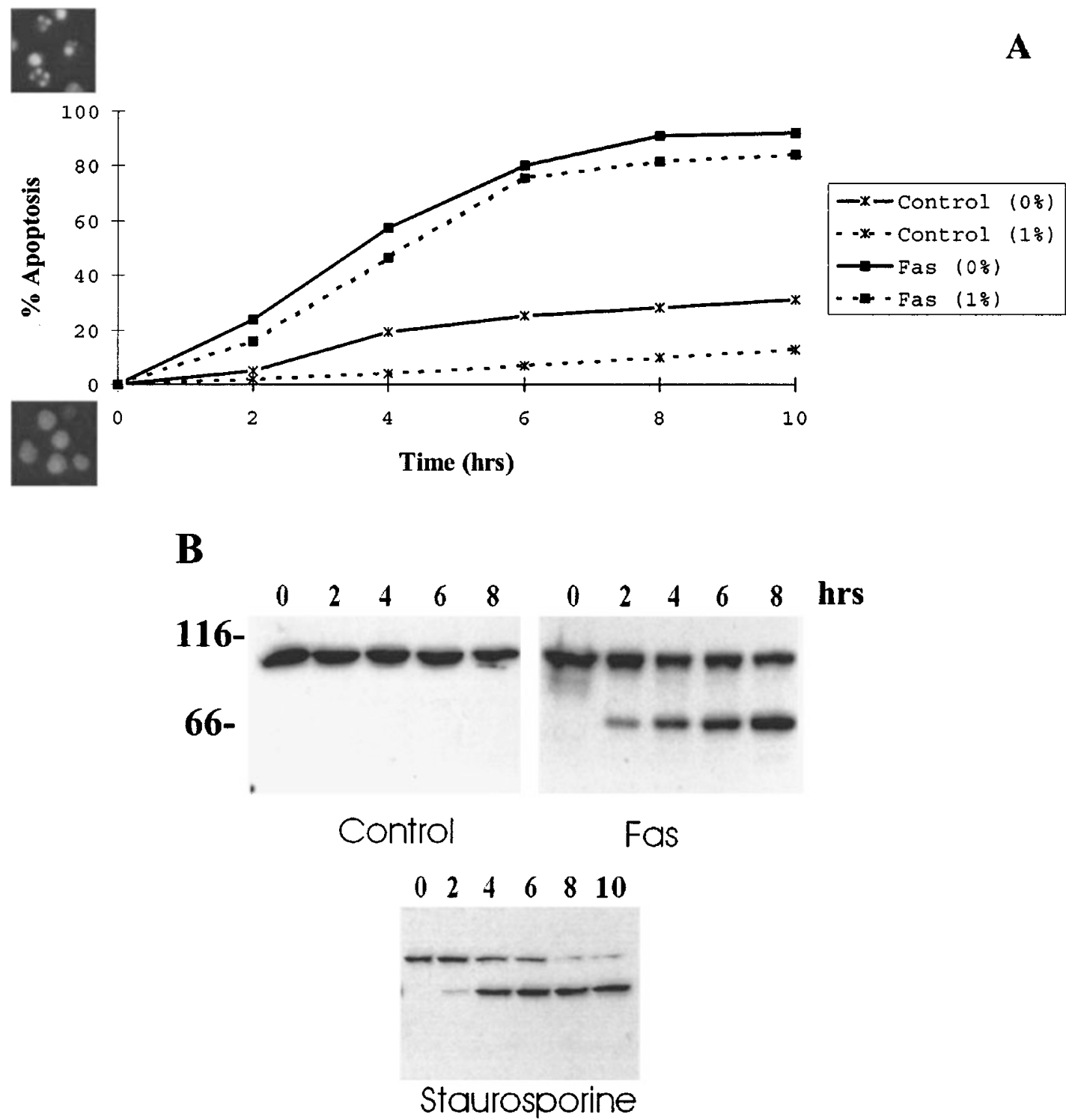

Figure 1 Apoptosis of Jurkat cells and cleavage of SATB1. (A) Cells were cultivated with or without addition of $1 \%$ serum. Apoptosis was triggered by addition of anti-Fas antibody. The percentage of cells displaying characteristic apoptotic morphological phenotypes were scored by microscopic investigation after staining with Hoechst-33258. Cells were counted in ten viewing fields for each time point in four independent experiments. Data represent mean values. (B) Total cell lysates $\left(1.5 \times 10^{5}\right.$ cell aliquots-Fas; $5 \times 10^{4}$ cell aliquots - staurosporine) from control (upper left panel), anti-Fas-treated (upper right panel) and staurosporinetreated (lower panel) Jurkat cells were separated by SDS-PAGE (10\% polyacrylamide [pa], blotted and probed with anti-SATB1 serum. Molecular weights in kDa as indicated on the left. Incubation time in hours is indicated on top

necrotic Jurkat cells revealed that SATB1 was unaffected during necrosis, measured 3 (50\% necrotic cells) and $6 \mathrm{~h}$ (85\% necrotic cells) past induction (Figure 2B, O3, O6, OST3, OST6). On the other hand, SATB1 was nearly completely proteolyzed when apoptosis was triggered by staurosporine alone (Figure 2B, ST6). Likewise, lamin B was cleaved in an apoptosis-specific manner (Figure 2B).

We, then, used a variety of protease inhibitors to gain more functional insight into the nature of SATB1 cleavage. In all cases, when cleavage was blocked, we could not detect any morphological evidence of apoptosis. This was true for TPCK (Figure 2B), inhibiting chymotrypsin-like proteases, as well as for the peptide inhibitors, blocking caspase activities. Ac-YVAD-cmk, primarily affecting activity of caspase-1, as well as DEVD-CHO, blocking caspase-3 action, both abrogated SATB1 and lamin B cleavage, respectively (Figure 2B, YVAD, DEVD). Inhibition of caspase activity was concentration-dependent for all peptide inhibitors, as exemplified in the case of benzoyloxycarbonyl-VAD-fmk, a pan caspase-inhibitor, which only partially blocked SATB1 cleavage when used at $1 \mu \mathrm{M}$ (Figure 2B, VAD1), but complete abrogation was observed at $10 \mu \mathrm{M}$ (Figure 2B, VAD10). In contrast, the serine protease inhibitor, TLCK (Figure $2 \mathrm{~B}$ ), and the calpain blocker calpeptin (Figure 2B, calp.) did not abolish cleavage of SATB1 or lamin B, respectively (compare to 

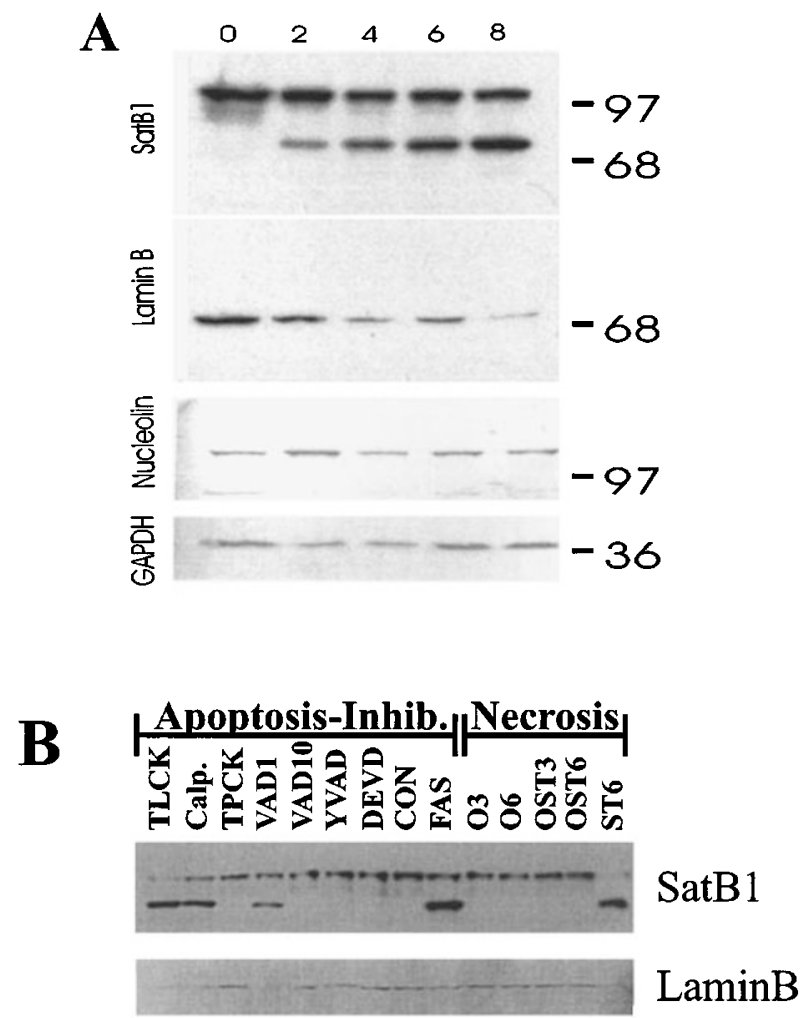

Figure 2 Characterization of cleavage substrates and verification of apoptosis-specific proteolysis of SATB1. (A) Total lysates of Jurkat cells from various time points (indicated in hours on top) during Fas-induced cell death were analyzed by immunostaining with anti-SATB1 serum and mAbs to either lamin B, nucleolin and GAPDH, respectively. Molecular weights in $\mathrm{kDa}$ are indicated on the right. (B) Inhibitor studies: Jurkat cells were pre-treated with cell-permeable protease inhibitors $30 \mathrm{~min}$ prior to induction of apoptosis with anti-Fas antibody. Total cell lysates, prepared $5 \mathrm{~h}$ after apoptosis induction, were analyzed for SATB1 cleavage by Western blotting (10\% pa). Untreated cells served as negative control (CON), anti-Fas-treated cells used as positive control (Fas). Necrosis: Apoptosis was induced with staurosporine for $6 \mathrm{~h}$ (ST6). Necrosis was triggered by treatment with oligomycin $(\mathrm{O} / 6)$ alone or in combination with staurosporine (OST3/6) for 3 and $6 \mathrm{~h}$, respectively. Cells were split into equal parts and one half analyzed for viability with the trypan blue exclusion assay, the remaining half for SATB1 cleavage by immunostaining. The blot was stripped with $0.2 \mathrm{M}$ glycine, $\mathrm{pH} 2.3$ for $2 \mathrm{~min}$ and re-probed for lamin B cleavage to verify apoptosis

Figure 2B, Fas). Therefore, data presented so far are consistent with an assumption that fragmentation of SATB1 was apoptosis-specific and most likely mediated by caspase activities.

\section{Nuclear matrix association of the cleavage product of SATB1}

Subcellular fractionation tests confirmed previous data ${ }^{46}$ that approximately $30-50 \%$ of SATB1 were solubilized from cell homogenates upon detergent treatment. We also found a considerable amount (20\%) solubilized after DNAse treatment. Concomitant application of distamycin A, competing with DNA-binding proteins for minor groove binding sites, did not increase the solubility of SATB1. Similar results were

obtained for the apoptotic $70 \mathrm{kDa}$ fragment, which, contrary to intact protein, was not extracted by DNAse treatment (all data not shown).

We separated nuclear matrix proteins (NMPS) from apoptotic (Anti-Fas) and control (Con) Jurkat cells (Figure 3 ) by high-resolution 2D-electrophoresis. We took samples from $4 \mathrm{~h}$ anti-Fas-treated cells for immunostaining to detect both full-length and digested SATB1, while silver stained 2D-gels were made from control and $8 \mathrm{~h}(80-90 \%$ degradation) anti-Fas treated Jurkat cells to demonstrate absence and emergence of SATB1-fragment spots more clearly. Immunostaining with anti-SATB1 serum clearly demonstrated three distinct (pl-range: $5.7-5.8)$ spots of the $70 \mathrm{kDa}$ degradation product (Figure 3, anti-Fas, small arrow). Intact SATB1, as in control preparations (Figure 3 Con, large arrow) focused as a smeary band (pl-range: 5.9-6.4). The spot appearance of the fragment lead to the assumption that SATB1 is post-translationally modified. Protein spots corresponding to the apoptotic SATB1 fragment were undetectable in controls after silver staining (Figure 3 left, Con, small arrow). Lamin B, a caspase target serving as control, was nearly completely degraded $8 \mathrm{~h}$ past anti-Fas induction (Figure 3, open circles, Con and anti-Fas). Conclusively, the detergent insoluble pool of the apoptotic $70 \mathrm{kDa}$ fragment remained associated with the nuclear matrix fraction and proteolysis exerted no obvious effect on the potential phosphorylation or ADP-ribosylation state of the molecule.

\section{Cleavage is not restricted to T-cells}

Low levels of mRNA of SATB1, predominantly expressed in the thymus, have been detected in other tissues. ${ }^{27}$ Using reverse transcriptase-polymerase chain reaction (RT$\mathrm{PCR})$, Cunningham and co-workers demonstrated the existence of SATB1 transcripts in several hematopoietic cell lines, ${ }^{53}$ among them promyelocytic HL-60 cells, which expressed much less of SATB1 than did Jurkat cells (Figure 4A).

To test whether cleavage of SATB1 was restricted to T-lymphoid cells, apoptosis of HL-60 cells was triggered by camptothecin. Anti-SATB1 staining of apoptotic HL-60 cell lysates revealed the presence of a fragment comparable in size to that observed in Fas-treated Jurkat cells (Figure 4A, compare HL-60, Cam and Jurkat, Fas). HL-60 cells, as expected, were not susceptible to anti-Fas treatment (Figure 4A, HL-60, Fas). Degradation of SATB1 in camptothecin-treated HL60 cells, was accompanied by morphological signs of apoptosis (data not shown) and occurred significantly faster than Fas-mediated death of Jurkat cells (Figure 4B). Jurkat cells were susceptible to camptothecin treatment, too, although the rate of apoptosis and concomitant cleavage of SATB1 was, compared to HL60 cells, delayed (Figure 4A, Jurkat and HL-60, Cam). Lamin B was proteolyzed similarly to SATB1, likewise independent of the cell type (Figure 4A, Lamin B). Conclusively, SATB1 was also a caspase target in cells, which express only minor amounts of SATB1. 

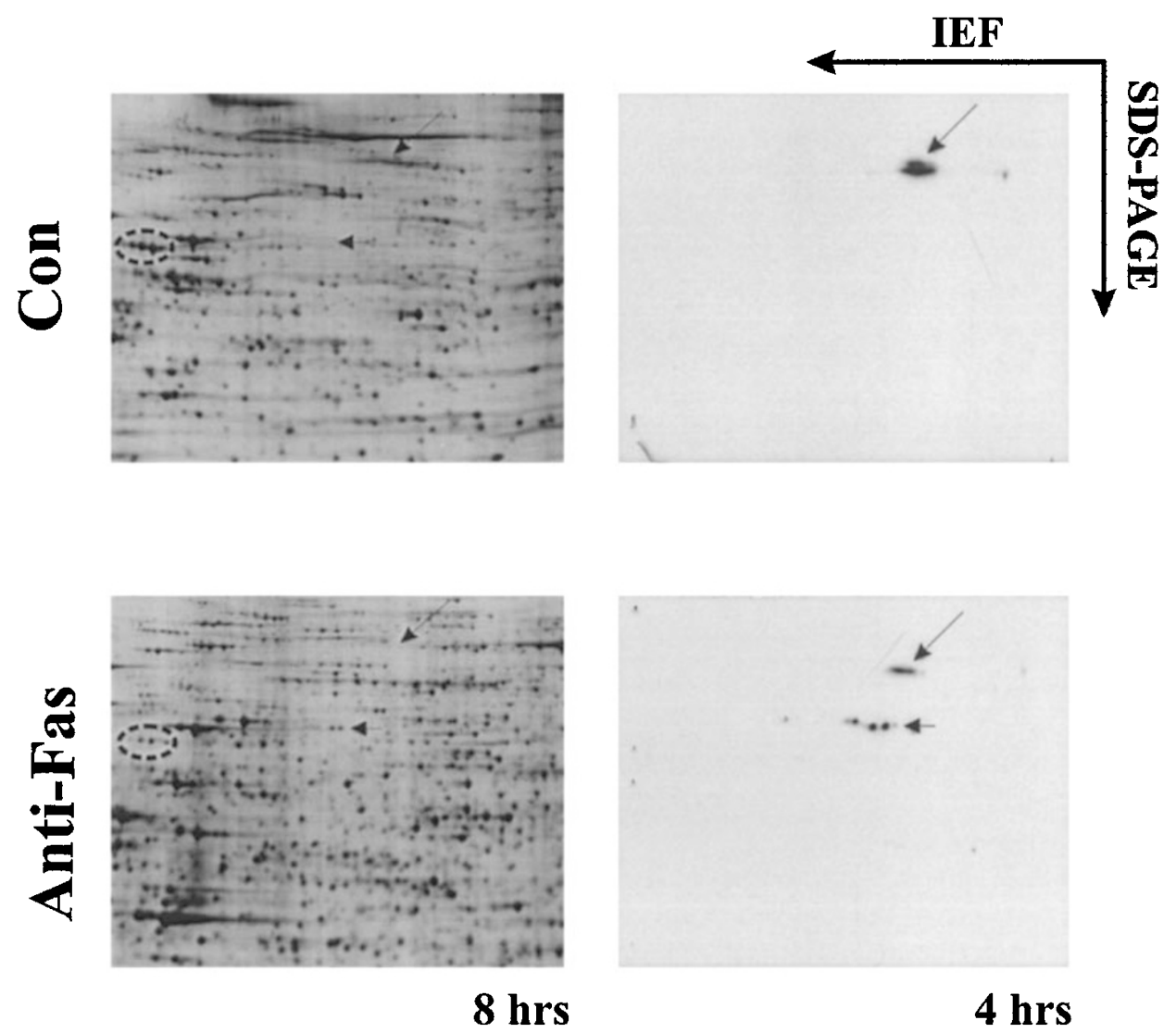

Figure 3 Nuclear matrix proteins (NMPs) from control and apoptotic Jurkat cells. The nuclear matrix protein fraction was prepared as described. ${ }^{76}$ NMPs from control (CON, upper panels) and anti-Fas induced Jurkat cells (lower panels), respectively, were separated by 2D-isoelectric focusing (IEF) gel electrophoresis and either silver stained (left panels) or subjected to Western analysis with anti-SATB1 serum (right panels). The large arrow indicates the position of intact SATB1, the apoptotic fragment is pointed by a small arrow. Open circle: position of lamin B. Note, that Western analysis was done on mini $2 \mathrm{D}-\mathrm{gels}(8 \times 6 \mathrm{~cm})$, while the silver stained pattern shows a representative inset from large $(16 \times 12 \mathrm{~cm})$ gels. This explains the apparent difference in pl positions of intact and degraded SATB1

\section{Cleavage site mapping}

In an effort to map the site of proteolytic cleavage and to study the intracellular changes during apoptosis we cloned the SATB1-cDNA by RT-PCR from Jurkat poly-A(+)-mRNA to produce recombinant SATB1 and mutants thereof. The integrity of the cDNA was confirmed by extensive restriction analysis and bacterially expressing a (His) ${ }_{6}$-tagged fusion protein, which (a) was recognized by anti-SATB1 serum and (b) showed the same anomalous electrophoretic mobility, as endogenous Jurkat SATB1 (data not shown).

We next constructed green fluorescent protein (GFP) chimeras, as outlined in the schematic drawings in Figures 5 and 7. A GFP-full length(fl)-SATB1 construct, designated 37, was transiently transfected into Jurkat cells by electroporation and total cell lysates were analyzed by Western blotting. Anti-GFP mAbs did not stain any crossreacting proteins in untransfected cells of wild-type, necrotic or apoptotic origin, while anti-SATB1 serum stained both intact and proteolyzed SATB1 in these lysates (Figure 5B). In 37-transfected Jurkat cells (Figure 5B, 37-Fas/-Camptothecin) exposed to anti-Fas or camptothecin, anti-GFP $m A b$ recognized the full length recombinant fusion protein with an apparent $M_{r}$ of 130000 . In addition, a cleavage product, possessing the N-terminally located GFP-molecule, with a molecular weight of $58 \mathrm{kDa}$ was detected (Figure 5B, arrow). Polypeptides of corresponding $M_{r}$ were stained by anti-SATB1 antibodies, which, as in lysates from untransfected cells, additionally recognized endogenous SATB1 and the apoptotic $70 \mathrm{kDa}$ fragment (Figure 5B, satb1). Staining intensities of the $\mathrm{N}$-terminal $58 \mathrm{kDa}$ fragments were low, suggesting little antigenicity of this region to SATB1 polyclonal antibodies, possibly because the serum was raised against recombinant SATB1 with an $\mathrm{N}$-terminal deletion of 59 amino acids. ${ }^{27}$ This may explain why we never detected this $\mathrm{N}$-terminal cleavage product in apoptotic lysates. A faint staining was observed, only when the fusion protein was overexpressed 15-20-fold.

In the deduced amino acid sequence of human SATB1 (accession number M97287) ${ }^{27}$ only one site bearing similarity to known consensus sequences for caspase cleavage $^{54}$ was detected. The 4 amino acid stretch VEMD (aa 251-254) matches cleavage motif sequence VExD, ${ }^{54}$ proposed for caspase- 6 (see Figure 5A). The calculated molecular weight $(57.3 \mathrm{kDa})$ of the expected $\mathrm{N}$ terminal fragment after in silico cleavage of the GFPchimera nearly exactly matched the experimentally derived value $(58 \mathrm{kDa}$, Figure $5 \mathrm{~A}, \mathrm{~B})$. Evidently, the C-terminal 

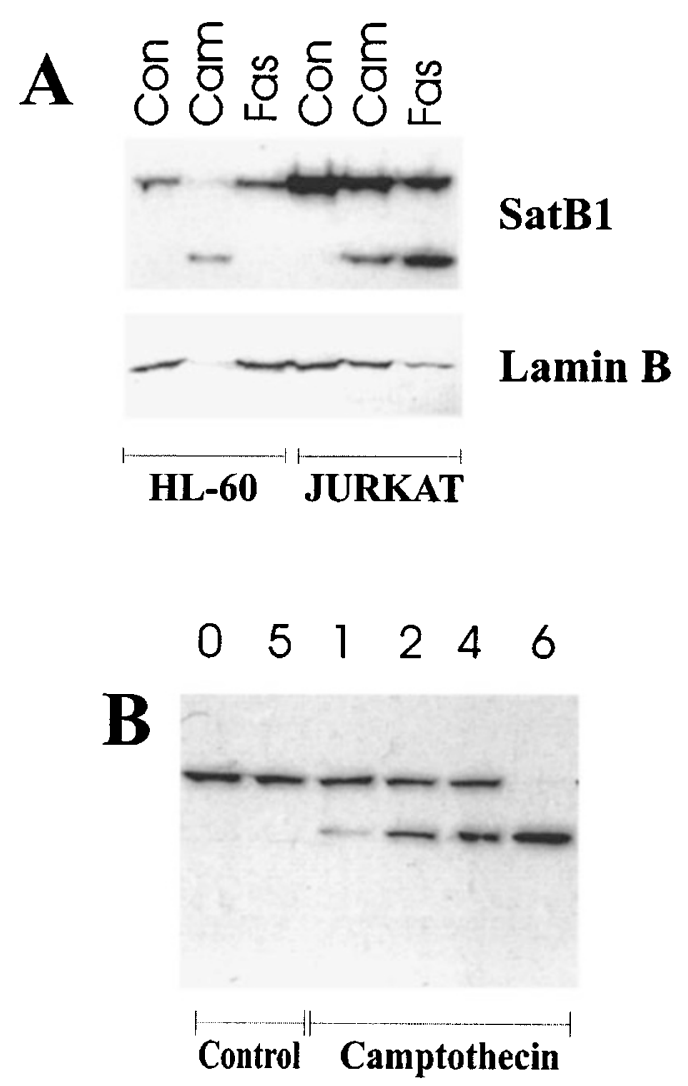

Figure 4 Cleavage of SATB1 during camptothecin-induced apoptosis in Jurkat and HL-60 cells. (A) HL-60 and Jurkat cells were treated for $5 \mathrm{~h}$ with camptothecin (Cam) or anti-Fas mAb (Fas). Total lysates ( $10^{5}$ cells) were probed for SATB1 cleavage $(7.5 \% \mathrm{pa})$. A duplicate blot was stained for lamin $B$. (B) Time course of SATB1 cleavage during camptothecin-induced apoptosis of HL-60 cells $\left(2 \times 10^{5}\right.$ cell aliquots per lane; $10 \%$ pa; anti-SATB1 staining). Untreated cells served as control. Incubation time $(h)$ is indicated on top

fragment, as depicted in Figure $5 \mathrm{~A}$ and verified by immunostaining as a prominent band (Figure $5 B$ ), is identical after proteolysis of both endogenous and recombinant SATB1. Apparent and calculated molecular weights of this C-terminal polypeptide, however, differed markedly by some $11 \mathrm{kDa}(70-58.4 \mathrm{kDa})$. We propose, that the polyglutamine stretch (Q15; aa 593-607) in this Cterminal fragment was responsible for the experimental discrepancy observed.

\section{Subcellular localization of the $\mathrm{N}$-terminal fragment in the course of apoptosis}

The N-terminal cleavage product lacks both domains considered responsible for MAR/SAR-binding of SATB1. ${ }^{55}$ Confocal microscopic images of GFP-SATB1 transfected Jurkat cells at various stages of apoptosis are shown in Figure 6.

In untreated cells SATB1 was found almost homogeneously distributed throughout the nucleus sparing structures reminiscent of nucleoli (Figure 6; Control). At early stages of apoptosis, when chromatin collapsed at the

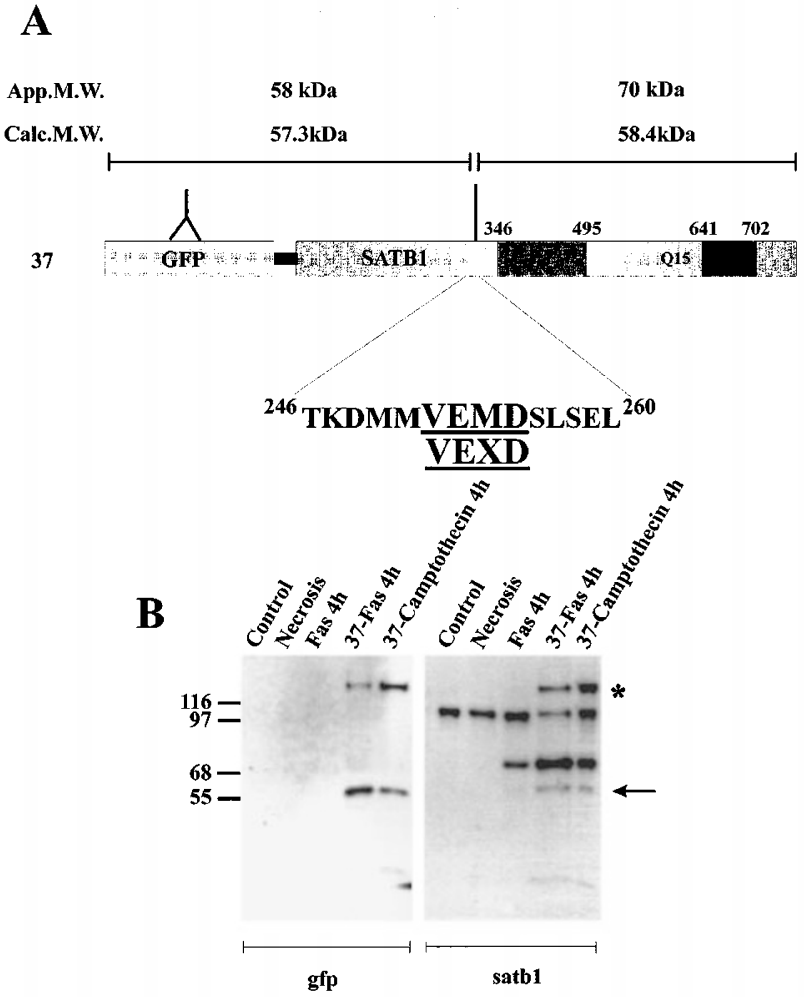

Figure 5 Cleavage site mapping using GFP-SATB1 fusion protein. (A) Schematic drawing of the GFP-SATB1 chimera (37). The gray-shaded box denotes the MAR/SAR-binding domain, the black box represents the homeodomain. Q15 indicates the presence of a glutamine-rich stretch. Numbers on top of the bar refer to amino acid positions in SATB1. The caspase- 6 consensus cleavage site is outlined. Apparent and calculated molecular weights of postulated fragments are shown on top. (B) Jurkat cells were transiently transfected with construct $37,12 \mathrm{~h}$ past transfection induced to undergo apoptosis for $4 \mathrm{~h}$ with either anti-Fas (37-Fas- $4 \mathrm{~h})$ or camptothecin (37-Camptothecin- $4 \mathrm{~h}$ ). Lysates from $2 \times 10^{5}$ cells after transient transfection were blotted $(7.5 \% \mathrm{pa})$ and probed with anti-GFP mAb (gfp) or anti-SATB1 serum (satb1), respectively. Untransfected cells of wild-type, necrotic and apoptotic (Fas $4 \mathrm{~h}$ ) origin are shown in the respective three left lanes in both panels. The arrow denotes the position of the $\mathrm{N}$-terminal fragment resulting from cleavage of the GFP chimera, the asterisk represents the intact recombinant protein. Molecular weights in $\mathrm{kDa}$ are indicated on the left

periphery of the nucleus, fragmented SATB1 remained in the nuclear interior, but was clearly excluded from DNA (Figure 6; $2 \mathrm{~h}$ ). At late stages of apoptosis, after breakdown of the nuclear envelope and advanced cleavage of SATB1, the N-terminal fragment localized to the cytoplasm almost lining emerging micronuclei (Figure $6 ; 4,6 \mathrm{~h}$ ). These data corroborated our proposal of caspase cleavage site, leaving an $\mathrm{N}$-terminal fragment, which loses the affinity to chromatin and relocates to structures free of DNA.

\section{Intracellular changes of SATB1 deletion mutants}

We produced GFP-tagged deletion constructs, depicted in Figure 7 denoted as 38, 39 and 40, to determine domains necessary for nuclear targeting and possibly reflecting subcellular localization changes during apoptosis. HeLa 
cells were used as transfection hosts for two reasons. First, to analyze the mutant proteins in a 'SATB1-negative' background, since expression is below the detection limit at the immunostaining level (data not shown). Secondly, to enable better morphological evaluation than in the small Jurkat cells, containing large nuclei and a small rim of cytoplasm. Subcellular localization results of all mutants were identical in both cell types (Figures 7 and 8B, and data not shown).

Full length SATB1 expressed in HeLa cells was also confined to the nucleus sparing nucleoli (Figure $7 ; 37$ ), as demonstrated above (Figure 6; Control). Deletion of the $\mathrm{N}$ terminal part $(\Delta \mathrm{N}$ aa $1-357)$ of the protein (Figure 7,38$)$,
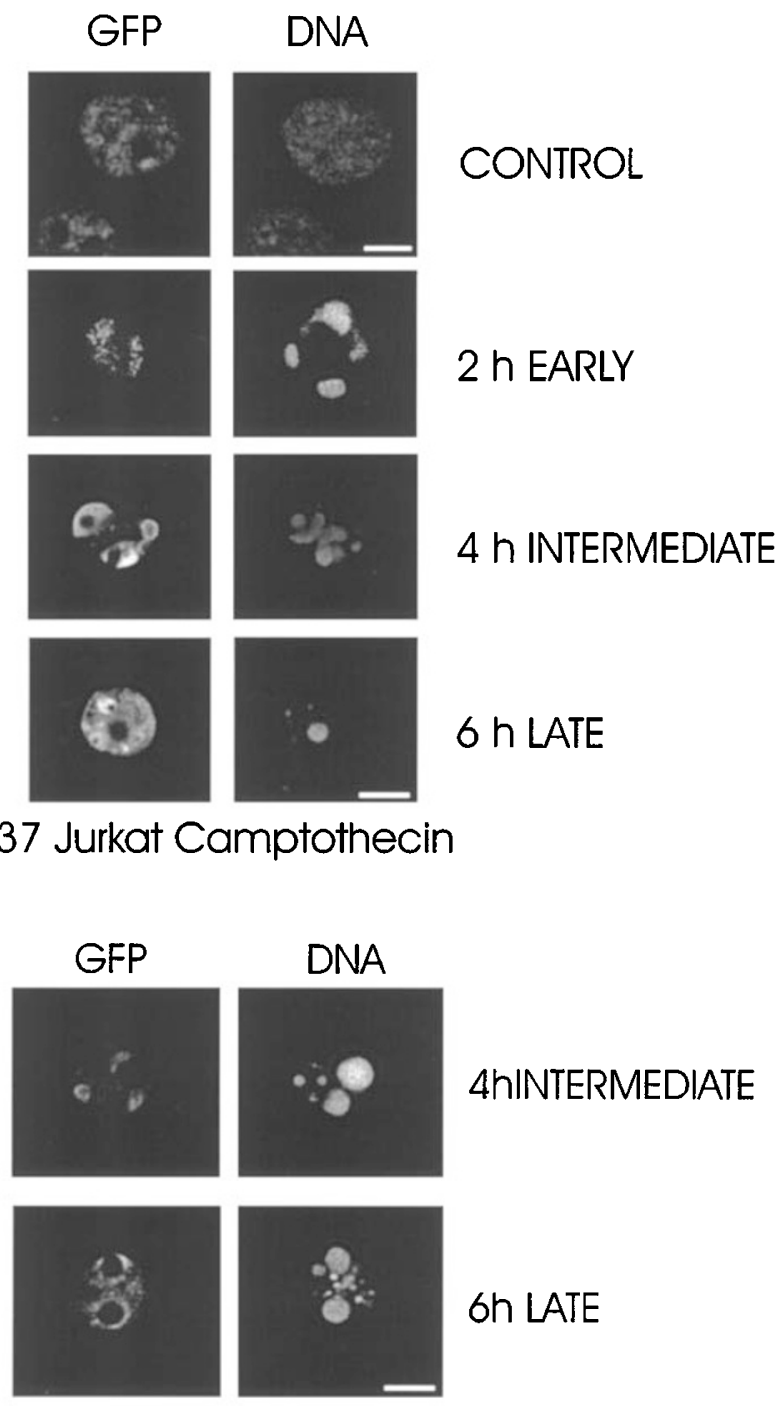

\section{Jurkat Fas}

Figure 6 The N-terminal fragment of cleaved SATB1 is not associated with chromatin. Jurkat cells were transiently transfected with construct 37 (Figure $5 \mathrm{~A})$ and apoptosis induced with camptothecin or anti-Fas, respectively. Confocal images of control and apoptotic cells, taken at various stages throughout apoptosis, delineate localization of the $\mathrm{N}$-terminal cleavage product by GFP fluorescence (GFP, left panels), counterstained for DNA with propidium iodide (DNA, right panels). Bar: $5 \mu \mathrm{m}$ reflecting an uncleavable C-terminal mutant (Figure $8 \mathrm{~A}$ ) lacking the VEMD-motif, resulted in partial localization to the cytoplasm (Figure 7; 38 and Figure 8B). A C-terminal deletion mutant $(\Delta \mathrm{C}$ aa 402-763), on the other side, localized to intranuclear dots with faint homogenous staining throughout the nucleus (Figure 7, 39; Figure 8B). One up to ten of these structures of differing sizes were observed. Structures were reminiscent of PML-bodies, ${ }^{56}$ sometimes appeared in a rim-like shape, similar to staining reported for pathogenic ataxin-1. ${ }^{57}$ Possibly, this C-terminal mutant has aggregation capability, reported for ataxin-1, huntingtin, and other proteins affected in neuronal polyglutamine diseases. ${ }^{57-61}$

Notably, if we further deleted the C-terminal part $(\Delta \mathrm{C}$ aa 223-763, Figure 7,40$)$, resulting in an also uncleavable (data not shown) $\mathrm{N}$-terminal mutant lacking the VEMD-motif, a homogenous nuclear staining, indistinguishable from that of fl-SATB1 (Figure 7, 37), was observed. The $\mathrm{N}$-terminal quarter of the molecule, although lacking a consensus nuclear localization signal, was therefore enough to target SATB1 to the nucleus. Removal of this N-terminal part, however, did only partially result in cytosolic localization (Figure 7, 38), suggesting more complex mechanisms determining nuclear transport of SATB1, involving proper folding and/or carrier proteins.

\section{The fate of SATB1-mutants during apoptosis}

Next, the fate of the mutants during apoptosis was examined. Jurkat cells were transiently transfected with constructs 3739 or the GFP control vector alone. Twelve hours post transfection, apoptosis was induced by addition of anti-Fas antibody. The transfection efficiencies varied with the vectors, which explained the different signal intensities in Western analysis.

Immunoblotting with anti-GFP mAbs confirmed the result described for GFP-fl SATB1 (Figure 5B), namely the appearance of a $58 \mathrm{kDa}$ fragment during apoptosis (Figure 8A, 37 apo). The same cleavage product was obtained by proteolysis of the C-terminally truncated polypeptide 39, which still harbors the proposed VEMD cleavage sequence. Cells transfected with the $\mathrm{N}$-terminal deletion construct 38, lacking the VEMD motif, expressed an uncleavable protein chimera of $90 \mathrm{kDa}$ (Figure $8 \mathrm{~A}$, 38 apo), though its calculated $M_{r}$ is 75500 . Thus, the Cterminus of SATB1 is responsible for the electrophoretic anomalies, as proposed above (Figure 5). Anti-SATB1 antibodies did only faintly stain overexpressed polypeptide 39 , but strongly recognized 38 , providing further evidence that the usually observed $70 \mathrm{kDa}$ fragment is of $\mathrm{C}$-terminal origin (data not shown). Morphological changes in 38- and 39-transfected HeLa and Jurkat cells (Figure 8B and data not shown) during apoptosis were similar to cells transfected with the full length protein chimera (Figure 6). The only difference observed was a delayed disorganization of 39-containing intranuclear domains during apoptosis (Figure 8B, 90'), resulting in localization of the $58 \mathrm{kDa}$ fragment lining micronuclei at very late stages of cell death (Figure 8B, $6 \mathrm{~h}$ ). 


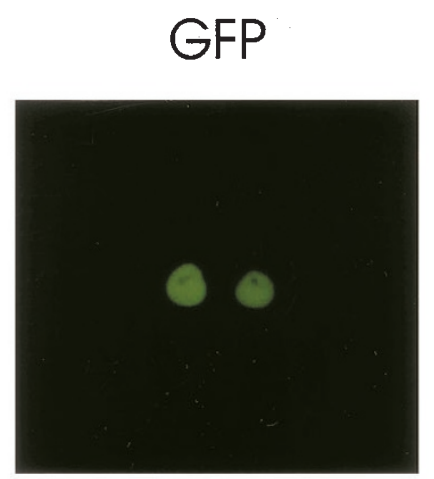

\section{MIXED LIGHT}

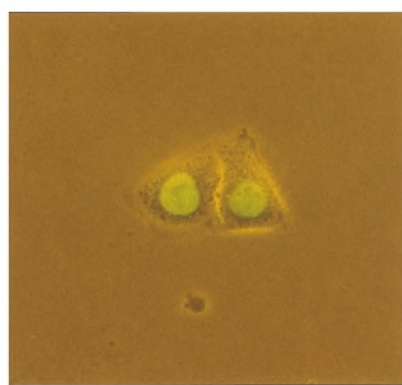

GPP SATB

\section{7}
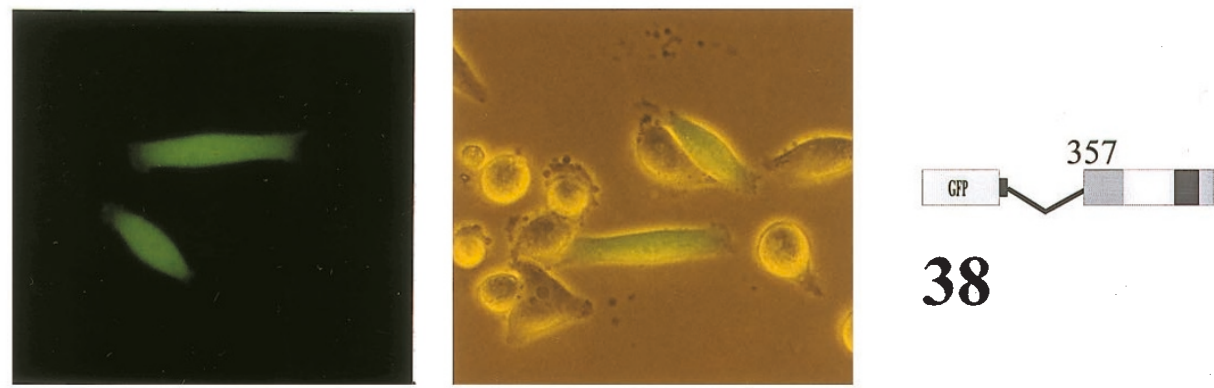

\section{8}
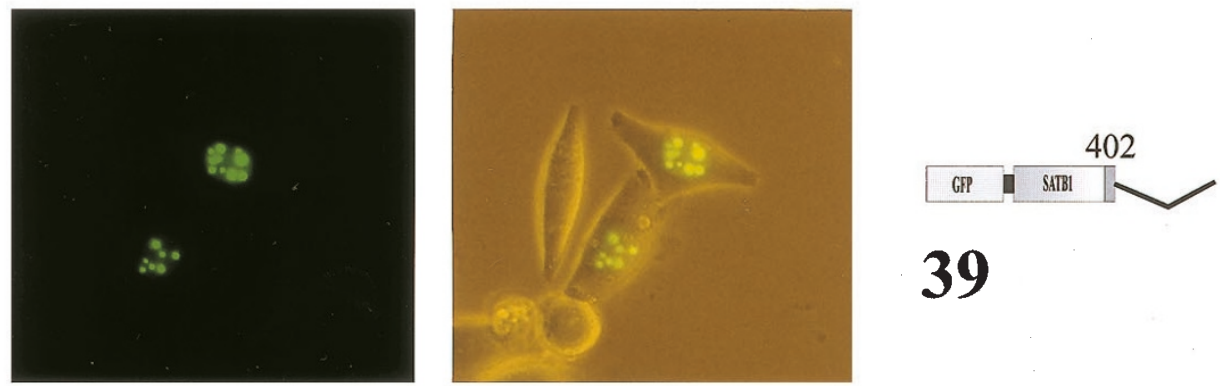

39
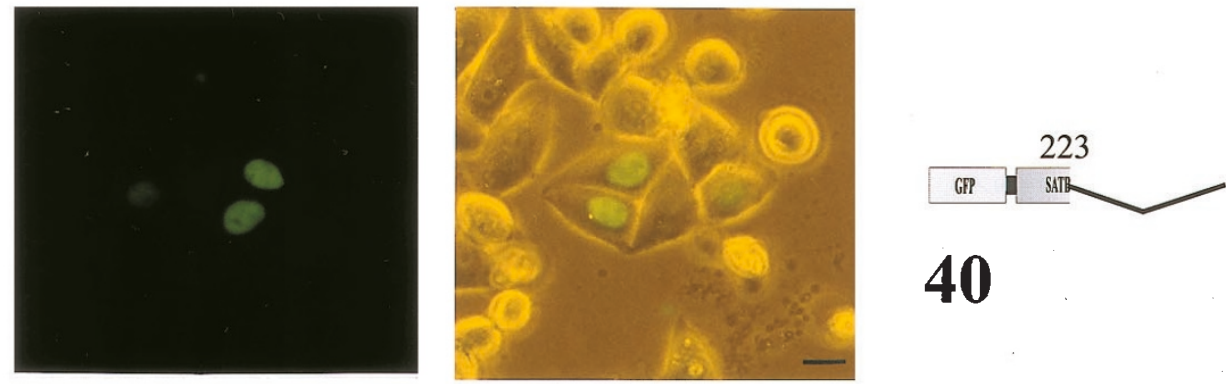

40

Figure 7 Intracellular localization of GFP-SATB1 constructs. HeLa cells were transiently transfected with GFP-tagged SATB1 constructs, the structure of which is schematically outlined on the very right. 37 , full length SATB1;38, $\Delta$ aa $1-357 ; 39, \Delta$ aa $402-763 ; 40, \Delta$ aa 223-763. Amino acid positions at which deletions start or end are indicated on top of the drawings, the domain structure is identical to that shown in Figure 5A. Representative fluorescent images from life cells are shown with the corresponding mixed-light (phase contrast plus fluorescence) pictures. Bar: $10 \mu \mathrm{m}$

\section{GFP is cleaved during apoptosis}

Unexpectedly, GFP was degraded during apoptosis (Figure $8 \mathrm{~A}$, GFP/GFPapo), resulting in the loss of approximately $2 \mathrm{kDa}$. Examination of the aa-sequence of GFP revealed the presence of a caspase-6-like cleavage motif VELD, spanning aa 17-20, but no other consensus sequences could be detected. The N-terminal localization of the site was confirmed by the fact, that we never observed GFP alone in apoptotic lysates from mutant-transfected cells. Proteolysis of 

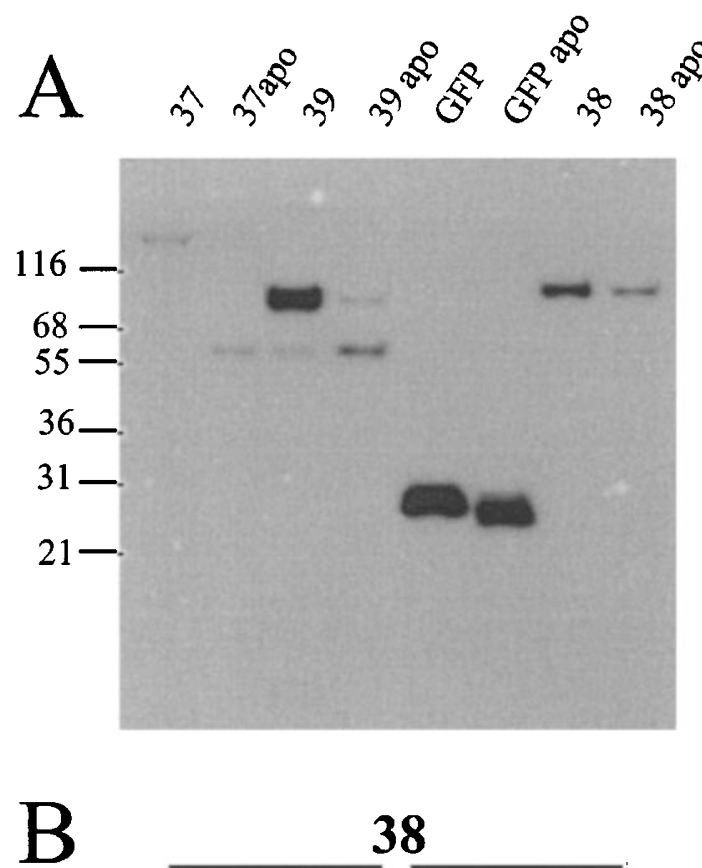

38
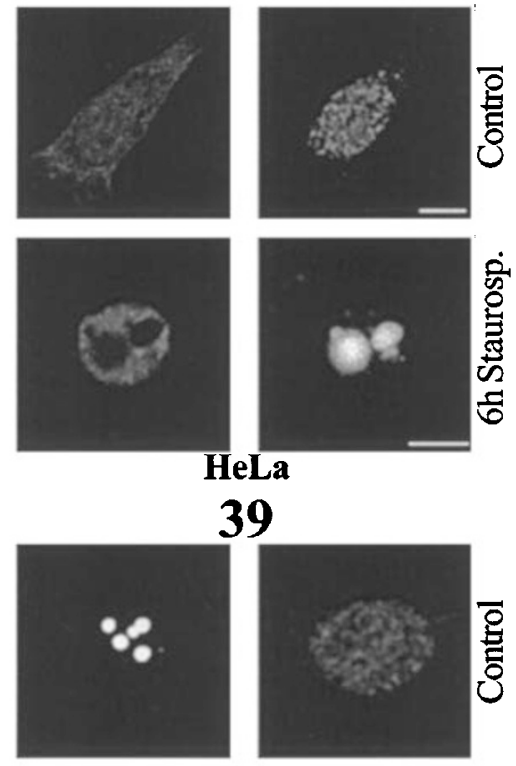

39
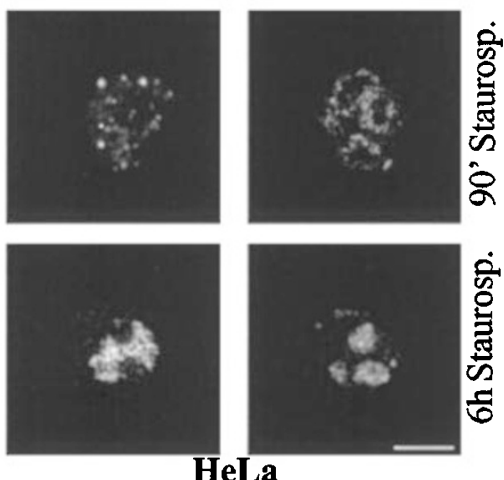

Figure 8 Proteolysis of GFP-SATB1 deletion mutants and cleavage of GFP. (A) Jurkat cells were transiently transfected with constructs 37 to 39 (see Figure 7) and GFP control vector only (GFP). Lysates of untreated and antiFas ( $5 \mathrm{~h}$ )-induced cells (suffix apo; $12 \mathrm{~h}$ post-transfection) were blotted $(7.5 \%$ pa) and probed with anti-GFP $\mathrm{mAB}$. Molecular weights in $\mathrm{kDa}$ are indicated on
GFP at this site did not influence its fluorescent properties, located in the central part of the protein, thereby exerting no influence on previously described morphological data.

\section{Discussion}

Based on recently published data on NMPs affected during apoptosis of serum-starved rat fibroblasts, ${ }^{45}$ we studied alterations of the nuclear matrix protein composition by systematically analyzing Fas-mediated cell death in Jurkat T-lymphoblastoid cells (Gerner, in preparation). Programmed cell death is accompanied by a collapse of nuclear architecture and cleavage of condensing chromatin into oligonucleosomal fragments. These events require disintegration of functional protein-protein and protein-DNA interactions, which maintain an ordered structure of the nucleus in intact interphase cells. M/SAR-binding proteins, commonly referred to as constituents of a nuclear matrix, interact with both, DNA and other NMPs. Three proteins of the MARbinding family have been described as caspase targets during apoptosis - namely, lamin $B,{ }^{37} \mathrm{NuMa},{ }^{12,40,41}$ and SAF-A. ${ }^{36}$ We identified another member, SATB1, to be proteolytically processed in an apoptosis-specific manner, yielding a stable $70 \mathrm{kDa}$ fragment, previously quoted by Martelli et al. ${ }^{18}$ which remains associated with the nuclear matrix protein fraction. The cleavage kinetics was similar to that observed for lamin $B$ and comparable to reported cleavage rates of SAF-A. ${ }^{36}$ Degradation in all cases started prior to or concomitant with the emergence of oligonucleosomal fragments. ${ }^{36,62}$ Considering the destruction of MAR-binding proteins as a prerequisite of DNA destruction and condensation, the fate of SATB1, though mainly expressed in T-cells, reflected that of the other affected ubiquitously occurring MAR-binding proteins.

Fas-mediated cell death is established as one of the major physiological transducing pathways leading to removal of unwanted cells. With respect to T-cell development, the role of Fas-signaling in peripheral clonal deletion or activation-induced suicide of mature $T$ cells is well established. ${ }^{63,64}$ whereas its contribution to negative selection of thymic cells remains controversial. ${ }^{65}$ Inhibitors of key enzymes, such as the protein kinase inhibitor staurosporine, and anti-cancer drugs (in our studies exemplified by the topoisomerase-I inhibitor camptothecin) supplement the rapidly growing list of apoptosis inducers. SATB1 cleavage was observed using these three inducers, involving Fas- and p53-dependent and -independent apoptotic pathways, demonstrating a convergence of pathways leading to exactly the same result. The link is represented by the cascade of pro-caspase activation, putting apoptotic signals into practice in a highly ordered

the left. (B) Confocal microscopy of control and apoptotic HeLa cells expressing GFP-tagged SATB1 mutants 38 and 39, respectively. Images were taken at various stages throughout apoptosis, induced by staurosporine. Changes in subcellular localization of the uncleavable polypeptide 38 or the Nterminal cleavage product from mutant 39 , respectively, were visualized by GFP fluorescence (GFP, left panels) and counterstained for DNA with propidium iodide (DNA, right panels). Bars: $10 \mu \mathrm{m}$ 
manner. ${ }^{3}$ Inhibitor studies demonstrated that proteolysis of SATB1 is caspase-dependent. The substrate specificities of caspases, having a strict preference for an aspartate (D) residue at the $\mathrm{P} 1$-position of common tetrapeptide substrates, have already been investigated in detail. ${ }^{54,66}$ Published in vitro data and mapping of cleavage sites in target proteins has led to the identification of consensus motifs, as e.g. DEVD for caspase-3 or VExD for caspase-6. Nonetheless, evidence exists for cleavage at unconventional sites. ${ }^{43}$ In addition, one motif may be cleaved by different caspases with different efficiencies, pointing to an evolutionary relation in sub-groups of the caspase family ${ }^{54}$ and the existence of differently branched cascades, dependent on the pro-apoptotic stimulus. ${ }^{67}$ Searching consensus motifs in the SATB1 aa-sequence, VEMD starting at aa-position 250, was the only tetrapeptide matching conventional substrate characteristics. VExD is the preferred motif for caspase- 6 , but has recently been shown to be, though less efficiently, cleaved by caspases 3 and 7 in vitro in keratin $18^{68}$ and by using artificial tetrapeptides. $^{54}$

Proteolysis of SATB1, although most abundantly expressed in the thymus, was not restricted to T-cells. At variance with data published most recently by Martelli, ${ }^{51}$ we observed fragmentation of SATB1 during apoptosis of unsynchronized promyelocytic HL-60 cells, induced by camptothecin at $1 \mu \mathrm{M}$. We could, however, confirm their data on the fate of nucleolin and SAF-A (data not shown). A possible heterogeneity in HL-60 cell clones, differently responding to topoisomerase-I inhibition, might explain our divergent results. Jurkat cells responded to camptothecin $(2-5 \mu \mathrm{M})$ with a slower proteolysis kinetics of SATB1 and lamin $B$, a result corroborating our findings in HL-60 cells, that SATB1 is degraded after camptothecin-induced induction of apoptosis, independent of the cell type.

Due to the anomalous electrophoretic mobility of SATB1, migrating at $103 \mathrm{kDa}$, compared to its calculated size of $84 \mathrm{kDa}$, cleavage site mapping by simple addition of the molecular weights of fragments seemed impossible. We, therefore, applied a molecular genetic approach for mapping the cleavage site by constructing GFP-SATB1 chimeras and analyzed their fates in apoptosis. This technique offers several advantages for apoptosis research: (a) lack of available antibody to the antigen is circumvented by using commercially available anti-GFP antibodies (b) the N-terminal fragment remains detectable, even if antigen-specific antibodies (primarily $m A b s$ ) fail to cross-react (c) due to the relatively large GFP-tag more exact size determination is enabled, if cleavage results in fragments of similar size (d) the fluorescent properties of GFP make it convenient to follow the sub-cellular localization of target proteins during apoptosis in life cells.

The fact, that unexpectedly, GFP itself is a caspase target by virtue, limited our application to using GFP Cterminally fused to proteins for simultaneous analysis of both fragments. GFP is most likely proteolyzed at aa position 18, where a caspase-6 VELD-motif is present, truncating $2 \mathrm{kDa}$ from the very $\mathrm{N}$-terminus. We identified this motif in all GFP-fluorescent shifted mutants commercially available. Nonetheless, cleavage exerted no obvious effect on the fluorescent properties, residing in the middle of the protein.

With respect to SATB1, our data from uncleavable mutants (Figure 8A, 38; and clone 40 (data not shown)) suggested that the cleavage site is located in the $\mathrm{N}$ terminal third of the protein, most likely resulting in the degradation at the VEMD sequence by caspases 6,3 or 7 or a combination of which. Since proteolysis kinetics was similar to that of the well-characterized caspase- 6 target, lamin $B,^{37}$ caspase- 6 was evidently active at this early stage of cell death. Cleavage left a C-terminal fragment still possessing the proposed MAR-binding domain and the homeodomain, ${ }^{55}$ possibly responsible for sustained association with the nuclear matrix. This interpretation was corroborated by the finding that deletion of only 11 aa at the $\mathrm{N}$-terminus of the MAR-binding domain ${ }^{55}$ resulted in partial localization of the mutant polypeptide to the cytosol (Figure 7,38 ). Furthermore, the present solubility tests proposed a MAR association of the apoptotic C-terminal fragment. We interpret the insolubility upon DNAse treatment as a result from impaired access of the enzyme to condensed chromatin. Conversely, the DNA-binding domain of another SAR-binding protein, SAF-A, is destroyed by caspase action. $^{36}$ Based on microscopic investigation, the $\mathrm{N}$ terminal remnant of SATB1 was undetectable in structures containing condensed chromatin during the various stages of apoptosis up to appearance of apoptotic bodies, independent of the apoptosis-inducing agent used.

Functional analysis of domains in SATB1 is restricted to in vitro MAR-binding capability and regions promoting this characteristic. $^{27,55}$ No function has yet been ascribed to the $\mathrm{N}$-terminal fragment generated by caspase-specific breakdown of SATB1 during apoptosis. Subcellular localization data on SATB1 are scarce and define SATB1 to be distributed throughout K562-cell nuclei in structureless dots. ${ }^{69}$ Electron microscopy points to a presence of SATB1 in fibrogranular structures, prominently appearing in apoptotic HL-60 cells, and to an association with condensed chromatin. ${ }^{70}$ These data have been generated using anti-SATB1 serum, ${ }^{27}$ which according to our experience has very little recognition potential to the $\mathrm{N}$ terminus, a fragment obviously remaining unassociated with chromatin. Transient expression of GFP-constructs in 'SATB1-negative' HeLa cells demonstrated full length SATB1 to be exclusively and almost homogeneously distributed throughout the nucleus with nucleolar exclusions. Using conventional immunofluorescence microscopy with the anti-SATB1 serum, Neri and co-workers ${ }^{69}$ reported a structured, partly granular, distribution of SATB1 in the nucleus. We cannot exclude, that overexpression of GFPSATB1 in HeLa cells exerted any influence on the subcellular distribution, explaining these divergent results. The intranuclear staining, however, did not change in stably transfected cell clones (data not shown). Furthermore, the $\mathrm{N}$-terminal third of the molecule was sufficient to target the molecule to the nucleus, although deletion of this part did not result in exclusive cytoplasmic localization of the SATB1-mutant. The appearance of nuclear domains, reminiscent of PML-bodies, in cells expressing the $\mathrm{N}$ terminal half of SATB1 might be explained by a high 
aggregation potential of this polypeptide, although staining was identical in stable transfectants (data not shown). Proper folding or additional protein-protein interactions might play a crucial role in proper nuclear localization.

Recent data point to an interaction of SATB1 with its transcriptional antagonist $\mathrm{CDP} / \mathrm{Cux}$, mediated via their MAR-binding domains, ${ }^{71}$ at least that of SATB1 remained unaffected by cleavage. Preliminary data from our lab suggest proteolysis of CDP/Cux itself during apoptosis, prospectively affecting its association to SATB1 (Meissner et al. unpublished data). On the other hand, proteolysis of SATB1 might abolish its effect on transcription of target genes, which in part may be mediated by the $\mathrm{N}$-terminal domain. Other M/SAR-binding transcription factors, such as the B-cell-specific Bright binds target sequences in a tetrameric state. $^{72}$ SATB1 was proposed to bind in a monomeric state in vitro, ${ }^{55}$ which, however, may not reflect in vivo conditions. Possible functional oligomerization might be hampered upon destruction of intact SATB1 during apoptosis.

Inhibition of transcription factors by apoptosis-specific cleavage has been reported in the case of $\mathrm{NF}-\kappa \mathrm{B}, \mathrm{Sp}-1$, STAT-1, and now for SATB1. ${ }^{17}$ To date the most important function ascribed to SATB1 is the transcriptional activation of the CD8-alpha gene. ${ }^{49}$ Fas-mediated cell death of misselected CD8 peripheral T-cells occurs only after inactivation of the CD8 gene by methylation. ${ }^{73}$ Moreover, continued T-cell receptor/CD8 co-engagement of major histocompatibility complex (MHC) molecules has been described to inhibit death signals for survival of correctly selected Tcells. $^{73}$ During thymocyte maturation the absence of a functional, survival supporting, CD8 molecule might be a prerequisite for proper removal of autoreactive cells. CD8 expression, agonized by SATB1, could thus play a crucial role in T-cell survival. In agreement with this proposal, a personal communication, quoted by Martelli ${ }^{18}$ and by Banan, ${ }^{49}$ on studies in SATB1 knock-out mice reports phenotypic changes, such as a reduced population of T-cells, CD8-positive cells being virtually absent and thymocytes being rendered extremely prone to apoptosis. In terms of biological relevance a, thus, implied antiapoptotic nature of SATB1, activating transcription of CD8 and possibly that of other survival factors, might therefore designate the protein as a caspase target. Impairment of SATB1-mediated transactivation of genes participating in survival activities may contribute to proper execution of cell death.

\section{Materials and Methods}

\section{Antibodies}

Anti-SATB1 rabbit polyclonal serum ${ }^{27}$ was a kind gift of Terumi KohwiShigematsu, anti-nucleolin monoclonal antibody (mAb) 3G4B2 was supplied by Roland Foisner. ${ }^{74}$ Anti-GAPDH mAb was purchased from Chemicon (Temecula, USA), anti-lamin B1 mAb from Oncogene Research (Cambridge, USA), anti-GFP mAb was obtained from Roche Diagnostics (Mannheim, Germany) and anti-Fas (CD95) mAb from Upstate Biotechnologies (Waltham, USA).

\section{Cell culture and induction of apoptosis/necrosis}

Jurkat, HL-60 and HeLa cells were routinely cultivated in RPMI-1640, supplemented with $10 \%$ fetal calf serum (FCS) at $37^{\circ} \mathrm{C}$ in a humidified atmosphere containing $5 \% \mathrm{CO}_{2}$. For induction of apoptosis Jurkat, $\mathrm{HL}$ 60 and HeLa cells were washed in serum-free medium and re-seeded at a density of $10^{5}$ cells $/ \mathrm{ml}$ in medium containing $1 \%$ FCS. Apoptosis was induced $15 \mathrm{~min}$ thereafter by addition of either anti-Fas (CD95) antibody (100 $\mathrm{ng} / \mathrm{ml}$ ) or camptothecin (Sigma, St. Louis, USA) to final concentrations of $1 \mu \mathrm{M}$ (HL-60) or $5 \mu \mathrm{M}$ (Jurkat), Staurosporine (Calbiochem, LaJolla, USA) was used at $1.25 \mu \mathrm{M}$. Parallel induction of apoptosis and necrosis was done as previously described by Leist et al. ${ }^{75}$ except that the medium contained $1 \%$ FCS and was free of glucose. In apoptosis inhibition assays, cells were pre-incubated for 30 min with protease inhibitors $(100 \mu \mathrm{M}$, except z-VAD-fmk [1 and $10 \mu \mathrm{M}$ ] and DEVD-CHO [200 $\mu \mathrm{M}]$ prior to application of anti-Fas antibody. All inhibitors were purchased from Calbiochem (LaJolla, USA).

\section{Subcellular fractionation}

Apoptotic and control Jurkat cells were washed twice with PBS. Total cellular lysates were obtained by dissolving the cell pellet $(170 \mathrm{~g}$, $5 \mathrm{~min}$ ) in $2 \times$ SDS - PAGE sample buffer (40 mM Tris-HCl, pH 6.8, $2 \%$ SDS, $2 \% \beta$-mercaptoethanol, $10 \%$ glycerol, $20 \mathrm{mM}$ DTT, $0.5 \%$ bromophenol-blue) with subsequent heating to $95^{\circ} \mathrm{C}$. For preparation of cytosol cells were lysed in $0.05 \%$ Nonidet P-40 in hypotonic buffer (10 mM HEPES/ $\mathrm{NaOH}, \mathrm{pH} 7.4,10 \mathrm{mM} \mathrm{NaCl}, 3 \mathrm{mM} \mathrm{MgCl}_{2}$ ). Nuclei were pelleted at $170 \mathrm{~g}$ for $10 \mathrm{~min}$ and the resulting supernatant centrifuged at $100000 \times g$ for $60 \mathrm{~min}$ to yield the supernatant cytosol. The detergent-soluble fraction was prepared by extracting cells in a mixture of $0.4 \%$ sodium-deoxycholate (DOC) and $0.5 \%$ Triton $X-100$ in hypotonic buffer for $5 \mathrm{~min}$ on ice. The homogenate was centrifuged at $200 \times g$ for $5 \mathrm{~min}$ and the nuclear pellet incubated in nuclease digestion buffer (10 mM PIPES, pH 6.8, $50 \mathrm{mM} \mathrm{NaCl}, 3 \mathrm{mM} \mathrm{MgCl}_{2}$, $0.25 \%$ Triton X-100, $300 \mathrm{mM}$ sucrose) including $40 \mu \mathrm{g} / \mathrm{ml}$ of DNAse I (Sigma, St. Louis, MO, USA) in the absence or presence of $200 \mu \mathrm{M}$ distamycin A (Sigma, St. Louis, MO, USA) for 15 min at RT. Insoluble protein was removed by centrifugation at $500 \times g$ for $5 \mathrm{~min}$. The nuclear matrix protein fraction was prepared as has been described in more detail by Gerner. ${ }^{76}$

\section{Cloning of SATB1}

Jurkat poly- $\mathrm{A}(+)$ mRNA was prepared and reverse transcribed into $(\mathrm{dT})_{15}$-primed-cDNA with poly-A(+)-mRNA-isolation- and 1st-strandcDNA-synthesis-kits according to manufacturer's instructions (Roche Diagnostics, Mannheim, Germany). SATB1 cDNA was amplified by $P C R$ using forward (SB1f) and reverse (SB1r) primers SB1f $5^{\prime}$ ACAGGAGCTCTGAGTATGGATCATTTGAAC-3' and SB1r 5'ACGCTGCAGTCTTTCAAATCAGTATTAATG-3' by 35 cycles of denaturation $\left(95^{\circ} \mathrm{C}, 15 \mathrm{~s}\right)$, annealing $\left(58^{\circ} \mathrm{C}, 20 \mathrm{~s}\right)$ and extension $\left(72^{\circ} \mathrm{C}, 3 \mathrm{~min}\right)$. PCR-products of corresponding size (2306 bp) were gel-eluted and cloned into pGEM-T vector (Promega, Mannheim, Germany) by conventional TA-cloning. SATB1 cDNA was further subcloned into His-tag expression vector pQE-30 (Quiagen, Hilden, Germany) and into pEGFP-C1 (37) (Clontech, Palo Alto, USA) by using primer-incorporated restriction sites $5^{\prime}-$ Sacl-3'-Pstl. N- (38) and C- $(39,40)$ terminal deletion constructs from full-length GFP-SATB1chimera 37 were made by digestion with Bglll (38), Eco72I-Smal (39), Scal-Smal (40) and subsequent re-ligation. 


\section{Transfection}

HeLa transfectants were obtained by liposome-mediated genetransfer using Tfx-20 (Promega, Mannheim, Germany) according to manufacturer's instructions. Jurkat cells were transfected by electroporation (EasyJect, EquiBio, Kent, UK) using a single pulse at 400 Volts and $1050 \mu \mathrm{F}$. Twelve hours later viable cells were collected by a standard Ficoll-Paque technique. ${ }^{77}$ Transiently transfected cells were viewed life under the fluorescence microscope or processed for confocal microscopy as described below.

\section{Scoring of apoptosis and viability}

Cells were harvested by combining floating and moderately adhering cells, washed twice in PBS, fixed for $10 \mathrm{~min}$ in $2 \%$ formaldehyde/PBS at room temperature, permeabilized with $\mathrm{PBS} / 0.2 \%$ Triton $\mathrm{X}-100$ for $1 \mathrm{~min}$ and were stained in $1 \mu \mathrm{g} / \mathrm{ml}$ Hoechst-33258 (Calbiochem, LaJolla, USA) for $2 \mathrm{~min}$. The percentage of cells displaying typical apoptotic nuclear morphology (crescent shaped condensed chromatin lining nuclear periphery; apoptotic bodies) was then determined empirically under the fluorescence microscope (Nikon Eclipse TE300). The Trypan-Blue (Sigma, St. Louis, MO, USA) exclusion assay was used to determine cellular viability.

\section{Two-dimensional electrophoresis, SDS-PAGE, and immunoblotting}

High resolution 2-D electrophoresis, SDS-PAGE and immunostaining was performed essentially as described. ${ }^{74}$ Polyacrylamide concentrations of 7.5 or $10 \%$, respectively, were used as indicated. Anti-SATB1 serum was diluted 1:3.000, anti-GAPDH, anti-nucleolin and anti-lamin $\mathrm{B}$ mAbs all were diluted 1:1.000 for Western analysis.

\section{Fluorescence microscopy}

For confocal microscopy, HeLa cells transfected with GFP-chimeras were grown on coverslips, fixed in $2 \%$ formaldehyde/PBS for $20 \mathrm{~min}$ at RT and permeabilized in $0.5 \%$ Triton X-100/PBS for 5 min. Counterstaining of DNA was done with propidium iodide (Sigma, St. Louis, MO, USA). Jurkat cells and apoptotic HeLa cells were treated alike but were sedimented on adhesion slides (BioRad, Hercules, USA) by gravitational force. Cells were viewed with the MRC 600 confocal microscope (BioRad, Hercules, USA). Conventional fluorescence microscopy of life cells was performed on a Nikon Eclipse TE300 inverted light microscope without prior treatment.

\section{Acknowledgements}

The authors wish to thank Terumi Kohwi-Shigematsu (University of California, Berkeley, CA, USA) for the generous gift of anti-SATB1 serum, and are indebted to Roland Foisner (Vienna Biocenter, Austria) for kindly providing anti-nucleolin (3G4B2) antibody. We highly appreciate fruitful discussions with Wilfried Bursch, Rolf Schulte-Hermann and Georg Sauermann and wish to thank the latter two for critical reading of the manuscript. Furthermore, we wish to thank Dieter Gelbmann and Editha Bayer for technical assistance and Ulrike Fröhwein for help with cell culture. This work was supported by a grant from the Herzfelder Stiftung, Vienna, Austria.

\section{References}

1. Steller $H$ (1995) Mechanisms and genes of cellular suicide. Science 267: 14451449

2. Hale AJ, Smith CA, Sutherland LC, Stoneman VE, Longthorne VL, Culhane AC and Williams GT (1996) Apoptosis: molecular regulation of cell death. Eur. J. Biochem. 236: 1-26

3. Thornberry NA and Lazebnik Y (1998) Caspases: enemies within. Science 281: $1312-1316$

4. Green DR (1998) Apoptotic pathways: the roads to ruin. Cell 94: 695-698

5. Leist M and Nicotera P (1998) Apoptosis, excitotoxicity, and neuropathology. Exp. Cell Res. 239: 183-201

6. Thompson CB (1995) Apoptosis in the pathogenesis and treatment of disease. Science 267: 1456-1462

7. Jäättelä M (1999) Escaping cell death: survival proteins in cancer. Exp. Cell Res. 248: $30-43$

8. Reed JC (1999) Mechanisms of apoptosis avoidance in cancer. Curr. Opin. Oncol. 11: 68-75

9. Williams GT (1991) Programmed cell death: apoptosis and oncogenesis. Cell 65: 1097-1098

10. Martin SJ and Green DR (1995) Protease activation during apoptosis: death by a thousand cuts? Cell 82: $349-352$

11. Kroemer G, Petit P, Zamzami N,Vayssiere JL and Mignotte B (1995) The biochemistry of programmed cell death. FASEB J. 9: 1277-1287

12. Weaver VM, Carson CE, Walker PR, Chaly N, Lach B, Raymond Y, Brown DL and Sikorska M (1996) Degradation of nuclear matrix and DNA cleavage in apoptotic thymocytes. J. Cell. Sci. 109: 45-56

13. Burgoyne LA (1999) The mechanisms of pyknosis: Hypercondensation and death. Exp. Cell Res. 248: 214-222

14. Ashkenazi A and Dixit VM (1998) Death receptors: signaling and modulation. Science 281: $1305-1308$

15. Green DR and Reed JC (1998) Mitochondria and apoptosis. Science 281: $1309-1312$

16. Evan $G$ and Littlewood T (1998) A matter of life and cell death. Science 281: $1317-1322$

17. Stroh C and Schulze-Osthoff K (1998) Death by a thousand cuts: an ever increasing list of caspase substrates. Cell Death Differ. 5: 997-1000

18. Martelli AM, Bareggi R, Bortul R, Grill V, Narducci P and Zweyer M (1997) The nuclear matrix and apoptosis. Histochem. Cell Biol. 108: 1-10

19. Berezney R and Coffey DS (1974) Identification of a nuclear protein matrix. Biochem. Biophys. Res. Commun. 60: 1410-1417

20. Fey EG and Penman S (1988) Nuclear matrix proteins reflect cell type of origin in cultured human cells. Proc. Natl. Acad. Sci. USA 85: 121-125

21. Cockerill PN and Garrard WT (1986) Chromosomal loop anchorage of the kappa immunoglobulin gene occurs next to the enhancer in a region containing topoisomerase II sites. Cell 44: 273-282

22. Mirkovitch J, Mirault ME and LaemmliUK (1984) Organization of the higher-order chromatin loop: specific DNA attachment sites on nuclear scaffold. Cell 39: 223-232

23. Boulikas T (1995) Chromatin domains and prediction of MAR sequences. Int. Rev. Cytol. 162A: 279-388

24. Kohwi-Shigematsu T, Maass K and Bode J (1997) A thymocyte factor SATB1 suppresses transcription of stably integrated matric-attachment region-linked reporter genes. Biochemistry 36: 12005-12010

25. Jenuwein T, Forrester WC, Fernandez HL, Laible G, Dull M and Grosschedl R (1997) Extension of chromatin accessibility by nuclear matrix attachment regions. Nature 385: 269-272

26. Adachi Y, Kas E and Laemmli UK (1989) Preferential, cooperative binding of DNA topoisomerase II to scaffold-associated regions. EMBO J. 8: 3997-4006

27. Dickinson LA, Joh T, Kohwi Y and Kohwi-Shigematsu T (1992) A tissue-specific MAR/SAR DNA-binding protein with unusual binding site recognition. Cell 70: 631-645

28. Izaurralde E, Kas E and Laemmli UK (1989) Highly preferential nucleation of histone $\mathrm{H} 1$ assembly on scaffold-associated regions. J. Mol. Biol. 210: 573585

29. Romig H, Fackelmayer FO, Renz A, Ramsperger U and Richter A (1992) Characterization of SAF-A, a novel nuclear DNA binding protein from HeLa cells with high affinity for nuclear matrix/scaffold attachment DNA elements. EMBOJ. 11: $3431-3440$ 
30. Renz A and Fackelmayer FO (1996) Purification and molecular cloning of the scaffold attachment factor B (SAF-B), a novel human nuclear protein that specifically binds to S/MAR-DNA. Nucleic Acids Res. 24: 843-849

31 Dickinson LA and Kohwi-Shigematsu T (1995) Nucleolin is a matrix attachment region DNA-binding protein that specifically recognizes a region with high baseunpairing potential. Mol. Cell. Biol. 15: 456-465

32. Will K, Warnecke G, Wiesmuller L and Deppert W (1998) Specific interaction of mutant $p 53$ with regions of matrix attachment region DNA elements (MARs) with a high potential for base-unpairing. Proc. Natl. Acad. Sci. USA 95: 13681 13686

33. Luderus ME, de Graaf A, Mattia E, den Blaauwen J, Grande MA, de Jong L and van Driel R (1992) Binding of matrix attachment regions to lamin B1. Cell 70: 949-959

34. Luderus ME, den Blaauwen J, de Smit O, Compton DA and van Driel R (1994) Binding of matrix attachment regions to lamin polymers involves single-stranded regions and the minor groove. Mol. Cell. Biol. 14: 6297-6305

35. Yanagisawa J, Ando J, Nakayama J, Kohwi Y and Kohwi-Shigematsu T (1996) A matrix attachment region (MAR)-binding activity due to a p114 kilodalton protein is found only in human breast carcinomas and not in normal and benign breast disease tissues. Cancer Res. 56: 457-462

36. Göhring F, Schwab BL, Nicotera P, Leist M and Fackelmayer FO (1997) The novel SAR-binding domain of scaffold attachment factor $A(S A F-A)$ is a target in apoptotic nuclear breakdown. EMBO J. 16: 7361-7371

37. Rao L, Perez D and White E (1996) Lamin proteolysis facilitates nuclear events during apoptosis. J. Cell Biol. 135: $1441-1455$

38. Oberhammer FA, Hochegger K, Fröschl G, Tiefenbacher R and Pavelka M (1994) Chromatin condensation during apoptosis is accompanied by degradation of lamin $A+B$, without enhanced activation of cdc2 kinase. J. Cell Biol. 126: $827-837$

39. Takahashi A, Alnemri ES, Lazebnik YA, Fernandes AT, Litwack G, Moir RD Goldman RD, Poirier GG, Kaufmann SH and Earnshaw WC (1996) Cleavage of lamin A by Mch2 alpha but not CPP32: multiple interleukin 1 beta-converting enzyme-related proteases with distinct substrate recognition properties are active in apoptosis. Proc. Natl. Acad. Sci. USA 93: 8395-8400

40. Hsu HL and Yeh NH (1996) Dynamic changes of NuMA during the cell cycle and possible appearance of a truncated form of NuMA during apoptosis. J. Cell Sci. 109: $277-288$

41. Gueth-Hallonet C, Weber Kand Osborn M (1997) Cleavage of the nuclear matrix protein NuMA during apoptosis. Exp. Cell Res. 233: 21-24

42 Tewari M, Quan LT, O’Rourke K, Desnoyers S, Zeng Z, Beidler DR, Poirier GG, Salvesen GS and Dixit VM (1995) Yama/CPP32 beta, a mammalian homologue of CED-3, is a CrmA-inhibitable protease that cleaves the death substrate poly(ADP-ribose) polymerase. Cell 81: 801-809

43. Samejima K, Svingen PA, Basi GS, Kottke T, Mesner-Jr PW, Stewart L, Durrieu F, Poirier GG, Alnemri ES, Champoux JJ, Kaufmann SH and Earnshaw WC (1999). Caspase-mediated cleavage of DNA topoisomerase I at unconventional sites during apoptosis. J. Biol. Chem. 274: 4335-4340

44. Duband-Goulet I, Courvalin JC and Buendia B (1998) LBR, a chromatin and lamin binding protein from the inner nuclear membrane, is proteolyzed at late stages of apoptosis. J. Cell Sci. 111: 1441-1451

45. Gerner C, Seelos C and Sauermann G(1998). Alteration of nuclear matrix protein composition during apoptosis in rat embryo cells. Exp. Cell Res. 238: 472-480

46. deBelle I, Cai ST and Kohwi-Shigematsu T (1998) The genomic sequences bound to special AT-rich sequence-binding protein 1 (SATB1) in vivo in Jurkat T cells are tightly associated with the nuclear matrix at the bases of the chromatin loops. J. Cell Biol. 141: 335-348

47. Dickinson LA, Dickinson CD and Kohwi-Shigematsu T (1997) An atypical homeodomain in SATB1 promotes specific recognition of the key structural element in a matrix attachment region. J. Biol. Chem. 272: 11463-11470

48. Liu J, Bramblett D, Zhu Q, Lozano M, Kobayashi R, Ross SR and Dudley JP (1997) The matrix attachment region-binding protein SATB1 participates in negative regulation of tissue-specific gene expression. Mol. Cell. Biol. 17: 5275-5287

49. Banan M, Rojas IC, Lee WH, King HL, Harris JV, Kobayashi R, Webb CF and Gottlieb PD (1997) Interaction of the nuclear matrix-associated region (MAR)binding proteins, SATB1 and CDP/Cux, with a MAR element (L2a) in an upstream regulatory region of the mouse CD8a gene. J. Biol. Chem. 272: $18440-18452$
50. EscalierD, AllenetB, Badrichani A and Garchon JH (1999) High level expression of the XIr nuclear protein in immature thymocytes and colocalization with the matrix-associated region-binding SATB1 protein. J. Immunol. 162: 292-298

51. Martelli AM, Bortul R, Fackelmayer FO, Tazzari PL, Bareggi R, Narducci P and Zweyer M (1999) Biochemical and morphological characterization of the nuclear matrix from apoptotic HL-60 cells. J. Cell. Biochem. 72: 35-46

52. Sawa A, Khan AA, Hester LD and Snyder SH (1997) Glyceraldehyde-3phosphate dehydrogenase: nuclear translocation participates in neuronal and nonneuronal cell death. Proc. Natl. Acad. Sci. USA. 94: 11669-11674

53. Cunningham JM, Purucker ME, Jane SM, Safer B, Vanin EF, Ney PA, Lowrey CH and Nienhuis AW (1994) The regulatory element 3 ' to the A gamma-globin gene binds to the nuclear matrix and interacts with special A-T-rich binding protein 1 (SATB1), an SAR/MAR-associating region DNA binding protein. Blood 84 $1298-1308$

54. Talanian RV, Quinlan C, Trautz S, Hackett MC, Mankovich JA, Banach D, Ghayur T, Brady KD and Wong WW (1997) Substrate specificities of caspase family proteases. J. Biol. Chem. 272: 9677-9682

55. Nakagomi K, Kohwi Y, Dickinson LA and Kohwi-Shigematsu T (1994) A novel DNA-binding motif in the nuclear matrix attachment DNA-binding protein SATB1. Mol. Cell. Biol. 14: 1852-1860

56. Dyck JA, Maul GG, Miller Jr WH, Chen JD, Kakizuka A and Evans RM (1994) A novel macromolecular structure is a target of the promyelocyte-retinoic acid receptor oncoprotein. Cell 76: 333-343

57. Skinner PJ, Koshy BT, Cummings CJ, Klement IA, Helin K, Servadio A, Zoghbi Y and Orr HT. (1997). Ataxin-1 with an expanded glutamine tract alters nuclear matrix-associated structures. Nature 389: $971-974$

58. Li SH and Li XJ (1998) Aggregation of N-terminal huntingtin is dependent on the length of its glutamine repeats. Hum. Mol. Genet. 7: 777-782

59. Scherzinger E, Lurz R, Turmaine M, Mangiarini L, Hollenbach B, Hasenbank R, Bates GP, Davies SW, Lehrach H and Wanker EE (1997) Huntingtin-encoded polyglutamine expansions form amyloid-like protein aggregates in vitro and in vivo. Cell 90: 549-558

60. Cooper JK, Schilling G, Peters MF, Herring WJ, Sharp AH, Kaminsky Z, Masone J, Khan FA, Delanoy M, Borchelt DR, Dawson VL, Dawson TM and Ross CA (1998) Truncated N-terminal fragments of huntingtin with expanded glutamine repeats form nuclear and cytoplasmic aggregates in cell culture. Hum. Mol. Genet. 7: $783-790$

61. Kim TW and Tanzi RE (1998) Neuronal intranuclear inclusions in polyglutamine diseases: nuclear weapons or nuclear fallout? Neuron 21: 657-659

62. Neamati N, Fernandez A, Wright S, Kiefer J and McConkey DJ (1995) Degradation of lamin B1 precedes oligonucleosomal DNA fragmentation in apoptotic thymocytes and isolated thymocyte nuclei. J. Immunol. 154: 3788 3795

63. Strasser A (1995) Life and death during lymphocyte development and function: evidence for two distinct killing mechanisms. Curr. Opin. Immunol. 7: 228-234

64. Nossal GJ (1994) Negative selection of lymphocytes. Cell 76: 229-239

65. Kishimoto H, Surh CD and Sprent J (1998) A role for Fas in negative selection of thymocytes in vivo. J. Exp. Med. 187: 1427-1438

66. Garcia-Calvo M, Peterson EP, Rasper DM, Vaillancourt JP, Zamboni R Nicholson DW and Thornberry NA (1999) Purification and catalytic properties of human caspase family members. Cell Death Differ. 6: 362-369

67. Slee EA, Harte MT, Kluck RM, WolfBB, Casiano CA, NewmeyerDD, Wang H-G, Reed JC, Nicholson DW, Alnemri ES, Green DR and Martin SJ (1999) Ordering the cytochrome $c$-initiated caspase cascade: Hierarchical activation of caspases-2, $-3,-6,-7,-8$, and -10 in a caspase-9-dependent manner. J. Cell Biol. 144: $281-292$

68. Caulin C, Salvesen GS and Oshima RG (1997) Caspase cleavage of keratin 18 and reorganization of intermediate filaments during epithelial cell apoptosis. J Cell Biol. 138: 1379-1394

69. Neri LM, Fackelmayer FO, Zweyer M, Kohwi-Shigematsu T and Martelli AM (1997) Subnuclear localization of S/MAR-binding proteins is differently affected by in vitro stabilization with heat or Cu2+. Chromosoma 106: 81-93

70. Zweyer M, Riederer BM, Ochs RL, Fackelmayer FO, Kohwi-Shigematsu T, Bareggi R, Narducci P and Martelli AM (1997) Association of nuclear matrix proteins with granular and threaded nuclear bodies in cell lines undergoing apoptosis. Exp. Cell Res. 230: 325-336 
71. Liu J, Barnett A, Neufeld EJ and Dudley JP (1999) Homeoproteins CDP and SATB1 interact: Potential for tissue-specific regulation. Mol. Cell. Biol. 19: 4918-4926

72. Herrscher RF, Kaplan MH, Leisz DL, Das C, Scheuermann R and Tucker PW (1995) The immunoglobulin heavy-chain matrix-associating regions are bound by Bright: a B cell-specific trans-activator that describes a new DNA-binding family. Genes Dev. 9: 3067-3082

73. Pestano GA, Zhou Y, Trimble LA, Daley J, Weber GF and Cantor H (1999) Inactivation of misselected CD8 T cells by CD8 gene methylation and cell death. Science 284: 1187-1191

74. Gotzmann J, Eger A, Meissner M, Grimm R, Gerner C, Sauermann Gand Foisner $\mathrm{R}$ (1997) Two-dimensional electrophoresis reveals a nuclear matrix-associated nucleolin complex of basic isoelectric point. Electrophoresis 18: 2645-2653 9
75. Leist M, Single B, Castoldi AF, Kuhnle S and Nicotera P (1997) Intracellular adenosine triphosphate (ATP) concentration: a switch in the decision between apoptosis and necrosis. J. Exp. Med. 185: 1481-1486

76. Gerner C, Holzmann K, Grimm R and Sauermann G (1998) Similarity between nuclear matrix proteins of various cells revealed by an improved isolation method. J. Cell. Biochem. 71: 363-374

77. Coligan JE, Kruisbeck AM, Margulies DH, Shevach EM and Strober W, (eds) (1995) In: Current Protocols in Immunology, Vol. 2 Chapter 7.1.2. John Wiley \& Sons Inc., New York 